\title{
Factors affecting the quality of apple juice
}

\author{
Svetlana Popel$^{*}$, Pavel Epifanov, and Larisa Yushan \\ PU «Scientific and Practical Institute of Horticulture, Viticulture and Food Technologies», \\ Chisinau, Moldova
}

\begin{abstract}
Annotation. This study reflects the research of technological factors of production that affect the quality of apple juice: temperature and time of sterilization, the influence of the type of used wort: gravity or a mixture of gravity and press fraction; the waiting time of the wort before the first heat treatment; as well as the presence of preheating. Regression equations have been developed that link the studied parameters and indicators of juice quality. The quantitative values of the characteristics of apple juice in the stated ranges, depending on the studied parameters, can be calculated by substituting the corresponding values in natural units into the developed regression equations.
\end{abstract}

\section{Introduction}

According to the current international documents, fruit and / or vegetable juice is a liquid product that is not fermented, but fermentable, obtained from healthy, ripe, fresh or preserved by cooling fruits, berries, vegetables or from semi-finished juices, which were stored under aseptic conditions from one or more mixed species, having a taste, color and aroma characteristic of the juice of fruits, berries and vegetables from which it is produced, canned by physical means [1-7].

Modern technology for the production of apple juice should ensure the nutritional and taste qualities of the juice, which are characteristic of apples as raw materials, as well as the high stability of the product during storage [8-14].

There is an opinion that the heat treatment has the most significant effect on the quality of the finished product. As a general principle, high temperatures and short holding times lead to significantly less negative changes in product quality than equivalent low temperatures and longer processing times in terms of achieving a technological effect [15-17].

The presented data in the scientific literature on the required values of the time and temperature of sterilization fluctuate within wide boundaries, since they depend, incl. and the type of canned product (direct juice or reconstituted juice). This is also important from the point of view of energy saving since, in addition to quality, a decrease in the pasteurization temperature by $10{ }^{\circ} \mathrm{C}$ gives an energy saving of $10 \%$ [8].

In the instructions for various technological lines for the production of apple juice, as well as in the scientific and technical literature, the heat treatment modes vary within wide limits: the sterilization temperature is from $94{ }^{\circ} \mathrm{C}$ to $120^{\circ} \mathrm{C}$ and the sterilization time is from $20 \mathrm{~s}$ to $120 \mathrm{~s}$. At the same time, contrary to popular belief, the recommended sterilization regimes

\footnotetext{
*Corresponding author: sspopeli@mail.ru
} 
assume for the lower level of the sterilization temperature - the lower level of the sterilization duration, and vice versa, a more severe temperature regime is used for a longer time. The cooling temperature of juice after filling into containers also varies widely - from $20{ }^{\circ} \mathrm{C}$ to $50{ }^{\circ} \mathrm{C}$.

It seemed important to us to investigate the influence of technological parameters of production on the quality, biochemical and nutritional value of apple juice, a semi-finished product intended for storage under aseptic conditions, further processing, and packaging in consumer containers, as well as for concentration and subsequent use for recovery.

In addition to the above parameters, this work also investigated the effect of the type of wort used: gravity flow or a mixture of gravity flow and press fraction; the waiting time of the wort before the first heat treatment; as well as the presence of preheating, since the influence of the latter factors on the quality of juice is not well covered in the literature.

\section{Materials and methods}

The influence of six technological factors of production on the quality of apple juice has been studied.

Factors investigated:

$\mathrm{X}_{1}$ - sterilization temperature

$\mathrm{X}_{2}$ - holding time during sterilization

$\mathrm{X}_{3}$ - wort waiting time before sterilization

$\mathrm{X}_{4}$ - name of the faction

$\mathrm{X}_{5}$ - presence $(+)$, absence (-) of preheating of wort

$\mathrm{X}_{6}$ - juice cooling temperature

In order to reduce the amount of work performed while maximizing the reliability of the results obtained, we used the method of extreme planning of the experiment. The method "pass - two 1/8 replicas $26-3$ " was used, the experiment included 20 experiments.

The experiments were carried out in a laboratory area designed for aseptic preservation of semi-finished juices in accordance with the developed plan.

The main criteria for determining the quality of apple juice were the organoleptic assessment of the samples by the professional staff of the tasting committee, as well as the analysis of a wide range of physical and chemical indicators of the studied juices.

Organoleptic evaluation was carried out by the institute's tasting committee on a 5-point scale. We studied the change in such quality indicators as: soluble solids according to GOST R 51433; mass fraction of alcohol according to GOST 25555.2; titratable acidity according to GOST R 51434; sugar (reducing, glucose, fructose, sucrose, total sugar) according to GOST R 51240, GOST R 51938; pH value according to GOST 51434; oxymethylfurfural according to GOST 29032; the amount of tannins and dyes according to the current method. Research data processed and presented in the form of mathematical models linking the investigated factors and response functions.

The computational procedure for determining the coefficients of the model is based on the least squares method. The adequacy of the obtained models was checked taking into account the given level of significance $\alpha=0.05$ using the Student and Fisher tests.

\section{Results and discussion}

Table 1 shows the results of studies carried out in accordance with the calculated matrix. 
The quantitative values of the characteristics of semi-finished apple juice in the stated ranges, depending on the parameters studied, can be calculated by substituting the corresponding values in natural units into the developed regression equations.

Table 1. Indicators of the quality of semi-finished apple juice

\begin{tabular}{|c|c|c|c|c|c|c|c|c|c|c|c|c|}
\hline \multirow[b]{2}{*}{ 익 } & \multirow[b]{2}{*}{$\begin{array}{l}0^{\circ} \\
\vec{\theta} \\
\frac{0}{0} \\
\frac{0}{3} \\
0 \\
0\end{array}$} & \multicolumn{6}{|c|}{ Sugar ,\% } & \multirow[b]{2}{*}{$\begin{array}{l}\underset{000}{\Xi} \\
\sum_{0}^{1} \\
0\end{array}$} & \multirow[b]{2}{*}{ I } & \multirow[b]{2}{*}{ 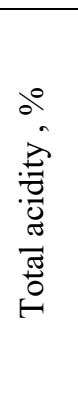 } & \multirow[b]{2}{*}{ 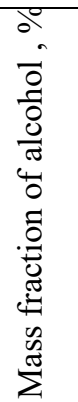 } & \multirow[b]{2}{*}{ 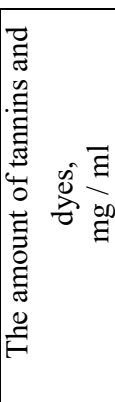 } \\
\hline & & 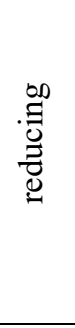 & 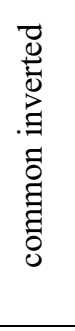 & 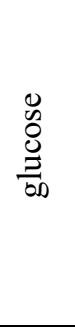 & 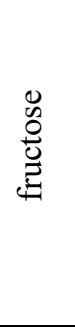 & $\begin{array}{l}\ddot{0} \\
\mathscr{0} \\
\stackrel{0}{0} \\
\ddot{n}\end{array}$ & 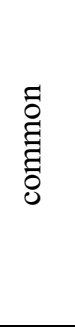 & & & & & \\
\hline 1 & 11.4 & 8.29 & 9.36 & 2.33 & 5.97 & 1.01 & 9.30 & 21.3 & 3.43 & 0.67 & 0.21 & 200.0 \\
\hline 2 & 11.4 & 8.35 & 9.54 & 2.52 & 5.83 & 1.13 & 9.48 & 20.0 & 3.41 & 0.66 & 0.30 & 212.5 \\
\hline 3 & 11.4 & 8.46 & 9.14 & 2.38 & 6.08 & 0.65 & 9.11 & 21.3 & 3.46 & 0.70 & 0.19 & 195.0 \\
\hline 4 & 11.3 & 8.46 & 9.23 & 2.62 & 5.84 & 0.73 & 9.19 & 21.3 & 3.45 & 0.69 & 0.23 & 220.0 \\
\hline 5 & 11.6 & 8.34 & 8.87 & 2.26 & 6.61 & 0.50 & 8.84 & 28.8 & 3.45 & 0.70 & 0.20 & 320.0 \\
\hline 6 & 11.3 & 8.33 & 8.74 & 2.48 & 5.85 & 0.39 & 8.72 & 21.3 & 3.45 & 0.62 & 0.22 & 250.0 \\
\hline 7 & 11.4 & 8.33 & 8.48 & 1.95 & 6.39 & 1.09 & 9.42 & 20.0 & 3.40 & 0.64 & 0.20 & 202.5 \\
\hline 8 & 11.6 & 8.55 & 9.42 & 2.29 & 6.26 & 0.82 & 9.37 & 18.8 & 3.42 & 0.64 & 0.20 & 222.5 \\
\hline 9 & 11.2 & 8.19 & 8.23 & 2.51 & 5.68 & 0.99 & 9.18 & 36.0 & 3.30 & 0.65 & 0.33 & 200.0 \\
\hline 10 & 11.0 & 8.19 & 8.23 & 2.51 & 5.68 & 0.99 & 9.18 & 32.5 & 3.30 & 0.64 & 0.30 & 185.0 \\
\hline 11 & 11.2 & 8.23 & 8.97 & 2.62 & 5.57 & 0.74 & 8.93 & 32.5 & 3.42 & 0.64 & 0.36 & 185.0 \\
\hline 12 & 11.2 & 8.35 & 8.97 & 2.65 & 5.68 & 0.59 & 8.94 & 37.5 & 3.40 & 0.64 & 0.33 & 180.0 \\
\hline 13 & 11.4 & 8.33 & 9.19 & 1.85 & 6.48 & 0.81 & 9.14 & 22.5 & 3.35 & 0.67 & 0.40 & 220.0 \\
\hline 14 & 11.4 & 8.33 & 9.40 & 1.74 & 6.59 & 1.01 & 9.34 & 21.3 & 3.27 & 0.64 & 0.41 & 205.0 \\
\hline 15 & 11.4 & 8.25 & 9.18 & 2.27 & 5.98 & 0.88 & 9.13 & 18.8 & 3.44 & 0.70 & 0.23 & 240.0 \\
\hline 16 & 11.4 & 8.25 & 9.28 & 2.07 & 6.18 & 0.97 & 9.22 & 27.5 & 3.40 & 0.64 & 0.26 & 205.0 \\
\hline 17 & 11.4 & 8.33 & 9.19 & 1.85 & 6.48 & 0.81 & 9.14 & 22.5 & 3.35 & 0.67 & 0.40 & 220.0 \\
\hline 18 & 11.4 & 8.31 & 9.18 & 2.03 & 6.28 & 0.83 & 9.14 & 42.5 & 3.31 & 0.62 & 0.31 & 172.5 \\
\hline 19 & 11.4 & 8.36 & 9.38 & 2.08 & 6.28 & 0.91 & 9.33 & 40.0 & 3.30 & 0.64 & 0.32 & 297.5 \\
\hline 20 & 11.4 & 8.25 & 9.28 & 2.07 & 6.18 & 0.97 & 9.22 & 27.5 & 3.40 & 0.65 & 0.26 & 205.0 \\
\hline
\end{tabular}

Table 2 shows the adequate interpolation regression equations, expressed in the natural values of the variables, established on the basis of the research carried out.

Analyzing the research results, it can be noted that the investigated parameters affect the quantitative values of the investigated indicators of the quality of apple juice. Moreover, there is both a decrease in the content of some substances and an increase in others, which correlates with the data of other authors [18].

The titratable acidity of apple juices in terms of malic acid, as a rule, is $5-9 \mathrm{~g} / \mathrm{l}$, but it can be 3.5-14.0 g/l and higher [19]. According to the results of our research, the acidity of apple juice is in the range of 6.2-7.7 g/l and the change in the acid content in the juice is approximately equally influenced by such factors as the waiting time for processing and the type of wort used, and the acidity is higher in the press wort. 
Table 2. Regression equations for the dependence of quality indicators of apple juice on technological parameters of production.

\begin{tabular}{|l|l|}
\hline $\begin{array}{l}\text { Qualitative indicator of semi-finished } \\
\text { apple juice, measurement unit }\end{array}$ & Equation of regression \\
\hline Organoleptic assessment, score & $\mathrm{Y}=3.719 \mathrm{X}_{0}-0.123 \mathrm{X}_{3}-0.094 \mathrm{X}_{4} ;$ \\
\hline Reducing sugars, \% & $\mathrm{Y}=8.345 \mathrm{X}_{0}-0.043 \mathrm{X}_{3} ;$ \\
\hline Glucose, $\%$ & $\mathrm{Y}=2.174 \mathrm{X}_{0}-0.179 \mathrm{X}_{3} ;$ \\
\hline Alcohol, \% & $\mathrm{Y}=0.268 \mathrm{X}_{0}+0.055 \mathrm{X}_{3}-0.032 \mathrm{X}_{5} ;$ \\
\hline Acidity, \% & $\mathrm{Y}=0.667 \mathrm{X}_{0}-0.009 \mathrm{X}_{1}-0.014 \mathrm{X}_{3}-0.010 \mathrm{X}_{4} ;$ \\
\hline The amount of tannins and dyes, $\mathrm{mg} / \mathrm{ml}$ & $\mathrm{Y}=224.218 \mathrm{X}_{0}+12.031 \mathrm{X}_{2}+11.093 \mathrm{X}_{4} ;$ \\
\hline OMF, mg/l & $\begin{array}{l}\mathrm{Y}=24.712 \mathrm{X}_{0}+2.962 \mathrm{X}_{1}+2.962 \mathrm{X}_{2}+3.112 \\
\mathrm{X}_{3} .\end{array}$ \\
\hline
\end{tabular}

Of the sugars in apples, fructose prevails 5.0-7.0 \%, the share of which in the total sugar content is $50-69 \%$, total sugar $9.0-14.0 \%$, glucose $1.17-3.64 \%$, sucrose $1,1-3.9$. In juices, the same trend persists. The results of our studies are consistent with the studies of other authors $[4,6]$. According to the results of our research in the production of juice on the content of glucose and, accordingly, reducing sugars, the factor of waiting for the wort before processing is significantly influenced, as evidenced by the obtained regression equations (table 2). With an increase in the waiting time for the wort before processing, the content of reducing substances decreases by $10 \%$, glucose - by $34 \%$, which indicates the initial consumption of glucose during storage of the wort. In this case, alcohol is formed, its acidity increases.

The acidity of the investigated juice is $0.64 \ldots 0.77 \%$.

In our studies, the sugar/acid ratio changes (12.6...14.7)/1, which corresponds to the recommendations of the FAO/WHO [FAO/WHO Principles and Practices of small and medium scale fruit juice processing] for apple juice - (10...18)/1. The ratio of sugar to acid in apple juice ranges from 12:1 to 18:1. Juices produced in the Republic of Moldova have a harmonious taste with a pleasant sugar/acid ratio.

Apple juice made from flawless raw materials is generally alcohol-free. The alcohol content in semi-finished apple juice is $0.2 \ldots 0.4 \%$. The greatest influence on the growth of alcohol is exerted by: the factor of waiting for the wort before processing - It increases the alcohol content in the juice, its preliminary heating reduces its content (Table 2).

The amount of tannins and dyes increases with the use of press wort, as well as with an increase in the duration of the sterilization process.

The content of OMF in semi-finished juice is $18.8 \ldots 40.0 \mathrm{mg} / \mathrm{l}$. The growth of OMF is affected by an increase in temperature in the duration of sterilization, as well as an increase in the duration of waiting for the wort before heat treatment.

Out of the studied factors, the organoleptic assessment of juices is significantly influenced only by the type of wort used; moreover, samples made from gravity juice received higher ratings.

\section{Conclusion}

The quantitative values of the characteristics of semi-finished apple juice in the stated ranges, depending on the parameters studied, can be calculated by substituting the corresponding values in natural units into the developed regression equations.

Analysis of the influence of the temperature and duration of sterilization on the quality of apple juice indicates that an increase in the sterilization temperature and holding time during sterilization adversely affect the nutritional value of the juice semi-finished product: 
- there is an increase in the amount of tannins and dyes, and this indicator is most influenced by the duration of sterilization;

- the content of OMF increases. As studies show, an increase in temperature and sterilization time equally affect an increase in OMF.

Analysis of the influence of the waiting time for wort in the queue for processing shows that this factor has a very significant effect on the quality of juice - a semi-finished product. With an increase in the waiting time of the wort before processing, the organoleptic assessment decreases, the amount of reducing sugars sharply decreases, the acidity decreases and the amount of alcohol increases, and, according to our data from reducing sugars, glucose reacts faster than fructose, as in melanoidin formation and during fermentation, which is confirmed by other authors.

The type of wort used also influences the quality of semi-finished apple juice. The tasting score for gravity juice is higher than for mixture of gravity and press wort.

\section{References}

1. K. Mihalev, R. Dinkova, V. Shikov, P. Mollov, In: G. Rajauria, B.K. Tiwari (ed.) Fruit Juices. Extraction, Composition, Quality and Analysis, 33-44 (Academic Press, 2018) https://doi.org/10.1016/B978-0-12-802230-6.00003-5

2. D. Kulev, I. Negrutsa, J. Hygienic Eng. Des., 3, 38-42 (2013) https://keypublishing.org/jhed/wp-content/uploads/2020/07/06.-Dmitry-Kulev-2.pdf

3. A. Petrenko, A. Kutyshenko, V. Tutelyan, In: G. Steier, K. Patel (eds) International Food Law and Policy, 1379-1407 (Springer, Cham., 2016) https://doi.org/10.1007/978-3-31907542-6 53

4. L. Servillo, A. Giovane, M.L. Balestrieri, G. Ferrari, D. Cautela, D. Castaldo, J. Agric. Food Chem., 60(1), 315-321 (2012) https://doi.org/10.1021/jf204286r

5. A. Septembre-Malaterre, F. Remize, P. Poucheret, Food Res. Int., 104, $86-99$ (2018) https://doi.org/10.1016/j.foodres.2017.09.031

6. L. Ayed, S. M'hir, M. Hamdi, J. Chem., 2020, 5790432 (2020) https://doi.org/10.1155/2020/5790432

7. C. Garcia; M. Guerin; K. Souidi; F. Remize, Beverages, 6(1), 8 (2020) https://doi.org/10.3390/beverages6010008

8. N.V. Makarova, D.F. Valiulina, Food Processing: Techniques and Technology, 29(2), 4246 (2013) https://naukaru.ru/en/nauka/article/27595/view

9. C.F. Verdu, N. Childebrand, N. Marnet, G. Lebail, F. Dupuis, F. Laurens, D. Guilet, S. Guyot, J. Sci. Food. Agric., 94(7), 1305-1314 (2014) http://doi/org/10.1002/jsfa.6411

10. N.N. Ivanova, L.M. Khomich, I.B. Perova, Probl. Nutr., 86(4), 125-136 (2017) http://doi.org/10.24411/0042-8833-2017-00068

11. É.S. Siguemoto, E. Purgatto, N.M.A. Hassimotto, J.A.W. Gut, LWT, 111, 853-860 (2019) https://doi.org/10.1016/j.lwt.2019.05.111

12. D.F. Valiulina, N.V. Makarova, I.A. Batkova, Life Sci. J., 11(12s), 791-796 (2014) http://www.lifesciencesite.com/lsj/life1112s/171_26495life1112s14_791 796.pdf

13. D.F. Valiulina, N.V. Makarova, I.A. Batkova, I.A. Platonov, Am. Eurasian J. Sustain. Agric., 8(12), 27-33 (2014) https://www.cabdirect.org/cabdirect/abstract/20143415005

14. D.F. Valiulina, N.V. Makarova, I.A. Batkova, Am. Eurasian J. Sustain. Agric., 9(4), 3136 (2015) http://www.aensiweb.net/AENSIWEB/aeb/aeb/2015/May/31-36.pdf

15. S.S. Popel, P.V. Epifanov, Realizări științifice în horticulturăa, oenologie și tehnologii alimentare, 426-433 (2020)

16. I.A. Pankina, E.S. Belokurova, Scientific journal NRU ITMO. Series "Processes and Food Production Equipment", 4(30), 58-64 (2016) http://doi.org/10.17586/2310-11642016-9-4-58-64 
17. I.A. Pankina, E.S. Belokurova, Scientific journal NRU ITMO. Series "Processes and Food Production Equipment", 1(31), 36-41 (2017) http://doi.org/10.17586/2310-11642017-10-1-36-41

18. G. Rajauia, B.K. Tiwari, Fruit Juices. Extraction, Composition, Quality and Analysis (Academic Press, 2018) https://doi.org/10.1016/C2014-0-02764-5

19. P.M. Finglas, M.A. Roe, H.M. Pinchen, R. Berry, S.M. Church, S.K. Dodhia, M. FarronWilson, G. Swan, McCance and Widdowson's The Composition of Foods, $7^{\text {th }}$ summary edition (Cambridge: Royal Society of Chemistry, 2015) 